\title{
VR Technology and Its Application and Prospect in the Field of University Education Technology
}

\author{
Huanxin Yang \\ Qilu University of Technology (Shandong Academy of Sciences), China.
}

\begin{abstract}
Virtual reality (VR) technology is a harmonious human-machine environment with three kinds of perceptual integration, such as sight, hearing and touch, which is generated by modern high-tech with computer technology as the core. Virtual reality technology combined with college education and teaching. It will definitely lead to a revolution in the way of education and teaching, and comprehensively improve the quality of education and teaching in colleges and universities. Virtual reality technology will have a profound impact on future education with its unique charm, adding a strong vitality to our education.
\end{abstract}

Keywords: virtual reality technology: colleges; application and prospect.

\section{Introduction}

With that VR hardware equipment researched and developed by world-leading companies comes in to use of consumer market, strong commercial application potential will rapidly drive the fast development of VR technology. At present, advanced western countries are constantly making breakthrough and innovation in the aspects including VR resource fabrication, peripheral hardware, mobile internet technology and artificial intelligence; VR has been gradually applied in many fields including medical treatment, education and military affairs due to practical and portable properties, experience at any time, and other interactive advantages of its equipment. Virtual reality technology is the cross and integrated product of many related disciplines. Its appearance will undoubtedly have a profound impact on education teaching in universities and add strong vitality to our education cause. Thus, related aspect of education teaching and talent training in universities is the reform issue that China faces at the moment.

\section{Overview of Virtual Reality Technology}

Virtual reality, called VR for short, is a brand-new comprehensive information technology rising in the late 20th century. VR adopts computer technology oriented modern high technology to generate three-dimensional vivid man-made virtual environment integrating a variety of senses including visual sense and tactile sense and it can truly simulate physical and functional things and circumstances that can be achieved in real world (or that are difficult or impossible to achieve). Users immerse themselves in a virtual environment through using various interactive devices to realize natural real-time interaction between users and the environment, and thoroughly obtain all kinds of spatial and logical information contained in the environment so as to generate the feel and experience of appearing in the site in person.

VR technology not only realizes transformation from "computer orientation" to "human orientation" but also realizes transformation from "one-dimensional information space suitable for computerization" and "multi-dimensional information space suitable for humanization". In traditional IC, information processing tool or environment is computer, experience skills (tacit knowledge) are stored in database in digital form, and high-end technology utilized is three-dimensional technology; however, construction of virtual space needs to be systematized, current model applied in education field is mostly the form of teaching experiment roaming, and it's cheap, convenient for popularization, and easy to operate due. 


\subsection{Characteristics of VR Technology}

\subsubsection{Immersion}

It lets the participant "truly" experience that he/she is the protagonist and has the feeling of being personally on the scene under simulation environment (virtual environment) supported by technology.

\subsubsection{Interactivity}

Knowledge information perceived by the user in virtual world makes the user enter the working state of system through multi-dimensional information and environment interaction and also data processing of feedback system to realize autonomous control of system operation

\subsubsection{Complex Perceptivity}

It's the most obvious characteristic of VR technology. It not only immerses the user but also makes the user accept the objective on multiple senses.

\subsection{High Simulation Art Experience of VR Technology}

VR is not only a cutting-edge technology but also an artistic practice of subject senses. During the subject's participation in the role process, it brings a kind of "high simulation" interaction enjoyment such as interactive virtual concert and virtual operating room. VR technology is utilized to conduct education or knowledge impartment.

\section{Problems Existing in Practical Teaching of University Education}

\subsection{Lack of Practice Experience}

Practical teaching content includes experience, practical training, social practice and curriculum design but it's less able to guarantee that teaching will not turn out to be a mere formality and students used to conduct stereotype fabrication in participating in practice and are not good at utilizing enlightening thought to innovate. Thus, paying attention to teaching practicability and strengthening the management and guidance of teaching experiment process appear to be particularly important.

\subsection{Short of Testing Equipment}

Under the condition that the state strongly advocates informationized education and multimedia education such as Mooc, most universities have almost reached completely perfect computer information-based education system in layout of equipment including computer and other media but equipment introduction of such new-type high-grade, high-precision and advanced technology as VR technology is still the greatest puzzle in teaching. In current market, VR equipment has great varieties and is still in an iterative process of initial exploration. VR headsets are sold at prices from RMB9.9 to RMB6888, which makes the entire VR market realize contention of a hundred schools of thought. The choice of testing equipment even needs a great auxiliary teaching system.

\subsection{Fuzzy Training Objective}

The cultivation system of universities is mostly all-round basic training but ignores special training of vocational skills, which makes students worry about the occupational direction and shortage of skill mastery. At present, demands of talent market and enterprises pay more attention to high professional qualification, high level and high quality. Thus, universities shall grasp all-round basic training and occupational skill training at the same time on the objective of teaching cultivation to make students better adapt to social needs and integrate development with them.

\subsection{Teachers' lack of Practical Experience in Enterprise Management}

Absence of following up teachers' single teaching means and technical researches on teaching is a major problem in education. A series of barriers including undefined objective and unsound system still exist in enterprise practices of teachers in some universities. 


\section{Suggestions on Teaching Technology Reform}

\subsection{Virtual Laboratory (V Lab)}

Virtual laboratory is a visual three-dimensional experimental environment that utilizes virtual technology including virtual reality technology, computer multimedia technology, database technology and network technology and has similar functions as traditional laboratory. In the "laboratory", students have enough experimental autonomy and are able to have simulation realization of various practical or even invisible and untouchable experiments with high risk and imaginary experimental scenes, which widens the limit in time and space of teaching experiment, reduces dependency of experimental teaching on objective material conditions, and can let students make experiments all day long. Virtual laboratory makes some boring and difficult experiments and practical training be interesting and convenient for understanding and mastery and it is good for motivating students' creative thinking, excavating students' potential, and training students' learning interest, practicing ability and scientific research ability. For some expensive precise instruments and meters, they not only allow students to use virtual instruments first but also make them practically operate real instruments and equipment to enrich perceptual knowledge.

\subsection{Virtual Classroom}

Virtual classroom will no longer be confined to physical classroom but changes traditional knowledge-imparting modes including classroom, textbook and courseware and makes abstract concepts and theories in teaching visualized, utilizes people's perception and cognition capacities for things in contact to comprehensively obtain a variety of information contained in the environment, enhance interaction in a collaborative environment, and intangibly expand time and space of teaching activities so as to change instilling model of traditional teaching and improve teaching efficiency in a natural and intimate atmosphere and under the real, dynamic and instanced interactive virtual teaching environment.

\subsection{Virtual Library}

Virtual library established on the basis of network environment and information electronization, utilizes internet to take electronic literature information resources as basis to establish virtual navigation system and make digitization of library resources to realize integration of various information resources and form rich and featured literature information resources. Book classification and arrangement are closer to reality and above reality. When learners enter virtual library to browse a variety of books, they only need to click corresponding virtual book gently with mouse. Scenes described in the book can truly reappear by means of virtual reality technology to let readers be able to experience and feel the artistic conception in the book and also chat with the writer in virtual world in the meantime of reading.

\subsection{Virtual Campus}

Virtual campus is a vivid constructed three-dimensional visualized virtual campus that is based on virtual reality technology to realize simulation of campus scene, browse and query of campus information, and combination of multimedia technology including image, sound, word, text and video. It has high interactive function and immersive realistic simulation function to let browsers be able to browse the entire campus merely through computer and network and feel graceful campus scenery, favorable teaching environment and teaching resources personally.

\subsection{Virtual Distance Education}

Virtual distance education is a distance education center of three-dimensional space integrating sound, image and other multimedia technology based on internet. It's vivid and lifelike learning environment and high immersion and interaction can make learners better obtain training of knowledge about culture, science and technology and basic skills. Virtual distance education breaks through traditional teaching model and forma new forms of teaching and learning. 


\section{Conclusion}

For development and research of higher education, the state shall profoundly realize its important and the urgency of implementation and increase policy support. Both theoretical support and oral support shall be put into work. For example, financial support shall be increased, professional talents shall be equipped for the development of both sides, integration of education and advantageous capacity shall be instructed, and experimental base meeting the needs of area development shall be established. These could strengthen the consciousness and confidence of cooperation between education and enterprises and promote coordinated development of both sides to some extent. In addition, the state shall help to establish a platform for international scientific research cooperation which is not only scientific research cooperation among countries along "the belt and road" but also exchange and learning from developed countries. Mutual research and cooperation are made to create new theories and technological achievements for better guidance on practice. Implementation of "the belt and road" strategy and enterprises' going abroad inevitably can't be separated from the development of higher education. "Going out" collaborative research will also be a renewable topic for a long time. With the development of practice and the improvement of era, we still need to continuously innovate new paths for integrative development of two sides so as to better adapt to opportunities and challenges brought by grand international development to our country.

\section{References}

[1]. Fei Linlin, Shan Hongwei. Virtual Reality Technology and Application [J]. Science and Technology Consulting, 2008 (36): 32-33.

[2]. Luo Qi. Research and Implementation of E-commerce Based on VR[J]. Journal of Weinan Teachers College, 2006( 5) : 31-32.

[3]. Huang Xin. Research on Virtual Teaching Application Based on VR Technology[J]. Journal of Jiangxi Institute of Education: Comprehensive Edition, 2008(6): 50-52.

[4]. Guo Tiantai. The application of virtual reality technology in higher education and its significance [J]. Journal of Ningbo University (Educational Science Edition), 2006, 28(1): 109-112.

[5]. Xu Hong, Liu Yu, Wang Lin. Research on the construction of network virtual laboratory [J]. Experimental Science and Technology. 2007, (04): 138-140. 